\title{
Creating an Ideal World: A Review of Work, Love, and Learning in Utopia: Equality Reimagined
}

\author{
Kathleen J. Fitzgerald ${ }^{1}$ (D)
}

Accepted: 24 August 2021 / Published online: 12 September 2021

(c) The Author(s), under exclusive licence to Springer Science+Business Media, LLC, part of Springer Nature 2021

The coronavirus pandemic has made the shortcomings of neoliberalism glaringly obvious. From the initial anemic public health response, particularly by the U.S. government, to the economic crisis resulting from the lockdown and global recession, and the disproportionate impact of COVID on marginalized members of society, from people of color to the elderly and the institutionalized, the pandemic has brought questions of social justice center stage (Branson-Potts, et al., 2020; Godoy \& Wood, 2020; Hummer, 2020; Jan, 2020; Kallberg, 2020). As such, the pandemic can be a catalyst for societal transformation. Indeed, we have seen "radical experiments in housing, criminal justice, education and more," from moratoriums on evictions, to tripling unemployment benefits, and the establishment of car-free, pedestrian friendly streets, as policy responses to the economic fallout from the pandemic (Cohen, 2021, p. 3). While such measures have been temporary, they provide fertile ground for thinking about what a more just society would look like. Critiques of neoliberalism and the inevitable limitations of a society that revolves around corporate profits, rather than an economy that addresses the needs of human communities, are not new (Yang, 2018). In Work, Love, and Learning in Utopia: Equality Reimagined, anthropologist Martin Schoenhals (2019) begins with the question, why is it "easy to criticize the world as it is, but hard to talk about the world as it should be?" (p. 1). While Schoenhals wrote this book prior to the pandemic, his approach to the subject matter makes it a useful accompaniment to these uncertain times.

While certainly not the first scholar to imagine what a utopian society might look like, Schoenhals' (2019) concept of "Utopia," (the name he assigns to the ideal world he outlines in this book) includes several unique characteristics. First, he avoids prioritizing issues of economic equality over addressing other sources of status differentiation. In his version of Utopia, the value of human relationships at home and in the workplace are primary, because they are the source of what he calls the "maximization of interactive joy." Second, Utopia requires the eradication of

Kathleen J. Fitzgerald

joykat88@email.unc.edu

1 Department of Sociology, University of North Carolina, Chapel Hill, NC, USA 
hierarchy, as it is a fundamental source of unhappiness for those on all levels of the social ladder. Thus, in order to maximize interactive joy, one must eliminate social inequality, as it is a key source of unhappiness. He does not overemphasize any form of hierarchy as being the ultimate cause of unhappiness. Hierarchies of wealth, power, gender, sexuality, ethnicity, and nation-states, for example, are all enemies of happiness and well-being. Thus, in his view, Utopia must seek to equalize the distribution of wealth, "but it also must equalize love and attention" (p. 3). While acknowledging that neither of those ideas are entirely novel, Schoenhals' argues that his work stands out from other theorists in that he uses scientific evidence to support the claim that hierarchy impedes human joy and happiness. Finally, Utopia will also provide every human being with decent food, housing, health care, and clothing because, "Freedom and joy can only occur in an environment where all humans are free from want" (p. 44).

Throughout the book, Schoenhals (2019) addresses anticipated critiques of his proposal. For example, he addresses whether societies can even be non-hierarchical-or does their current ubiquity suggest that social stratification is somehow innate to the human condition? Additionally, can humans live cooperatively and with compassion? Schoenhals takes an interdisciplinary approach to answering these questions. He first turns to evolutionary biology to explore research on joy and happiness, linking the emergence of these positive emotions to the rewards of parenting, which he argues eventually extends to other, non-parenting, relationships. He sums this up by stating, "joy evolved to reinforce the parental behaviors so crucial to mammalian survival" (p. 9, italics in the original). He then investigates the emergence of hierarchy among humans and animals, concluding that such inequality emerges in conjunction with the emotions of anger, aggression, fear, sadness, and depression. While anger is connected to the drive for individual survival, joy is connected to prosociality. Turning to the anthropological literature, Schoenhals finds that, "Humans actually lived a sharing, cooperative, and egalitarian life for most of the time we've been on earth... Hierarchy is the anomaly. We've only become hierarchical very late in our history on earth - only in the last $5 \%$ of our time in existence" (p. 28, italics in the original). Indeed, the emergence of human hierarchies coincided with the rise of the state, approximately 6000 years ago. He then turns to psychological research on child development to support his thesis, much of it arguing that children have a natural inclination toward cooperativeness and the ability to sympathize with others. In other words, we must learn to be competitive. Finally, he addresses research by primatologists who argue that we have overemphasized the capacity for violence and conflict among our primate relatives, and overlooked their capacity for empathy and cooperation. Moreover, it turns out that environmental conditions, such as resource scarcity, dictate whether most primates are peaceful or aggressive. In the end, his interdisciplinary answer as to whether societies can be non-hierarchical, is quite convincing.

Schoenhals (2019) argues that not only should our relationships bring us happiness, but so should work and learning. His argument rings true in the face of the pandemic-related lockdowns, and the subsequent shifts to online learning, teaching, and working. Many of us deeply miss those casual interactions with workplace colleagues and sharing laughs in the halls. We miss interacting with students in-person, 
in lecture halls, in office hours, or in random, chance encounters on campus. Before most of us were forced by the Covid-19 pandemic to acknowledge how important such relationships were to us, Schoenhals recognizes that, in addition to generating income and offering people a sense of personal satisfaction, work gives "us joy from the interaction between individuals," (p. 3).

Schoenhals (2019) emphasizes that one of the biggest problems with educational systems today is that, while learning is usually an enjoyable activity, schools are often structured to take the gratification out of it. As he points out, "What we learn at school is sometimes pleasurable, but the pleasure motive is invalidated by society. It is invalidated by elites, who never ask how to make schools more fun, but only more efficient," (p. 195). Unsurprisingly, he critiques schools for their hierarchical structures, where they sort students into a pecking order of achievement that then contributes to a hierarchy of adult workers. It is this very hierarchical structure that, "crowds out joy... [and] keeps school learning from being the joy that it should be," (p. 198). His suggestions for learning in Utopia include eliminating grades, making learning a lifelong activity (rather than just something young people engage in), shifting the purpose of learning from career preparation to pleasure, and making learning a collective endeavor to whatever extent is possible. For those of us who teach, one can imagine how the classroom dynamic would improve if these suggestions were implemented. To have a room full of people who actually want to learn for its own sake-rather than simply viewing themselves as fulfilling enough requirements to become credentialed so that they can enter a particular profession-is an enticing idea.

A unique contribution of this work is Schoenhals' (2019) placement of the equality of sexuality, gender, and love as primary, rather than subordinate to economic justice, partially accomplished through his notion of egalitarian sexuality. Egalitarian sexuality promotes a new kind of sexuality that deemphasizes attraction based upon gender. It erases gender and the hierarchy based on gender, promoting a genderless sexuality, where "humans will be encouraged to feel attraction to any other human," (p. 63). He argues this is essential, because it will not only help end intergender hierarchies, but also help reduce intragender hierarchies based upon sex that manifest, for instance, in men being socialized to treat sex as a conquest and competition. This, obviously, degrades the people being sought out for conquest (most often women), but it is also problematic because it contributes to men seeking sex simply to "score", rather than for its intrinsic pleasure. Finally, egalitarian sexuality means there would be no hierarchy of physical attractiveness, as all people deserve to love and be loved in return. While this might sound difficult to achieve, Schoenhals argues that this requires a shift away from understanding attraction as individualized, and instead seeing it as socially and culturally proscribed.

The path to egalitarian sexuality involves socializing people to new values oriented around the concept of compassion. This section of Schoenhals' (2019) argument is to be commended for taking media seriously - both how it contributes to the hierarchy of physical attraction that exists today, and how it can be transformed to encourage people to learn to be attracted to compassionate behaviors, rather than to looks, money, or status. He suggests that in Utopia, media can celebrate compassionate individuals and ordinary acts of everyday kindness, as well as emphasize 
stories of individuals, who experience a deficit of love as a way to bring them positive attention and, potentially, love. This may sound overly idyllic to many readers, but it would certainly help transform our current culture away from one that celebrates "influencers," the Kardashians and others, who are famous for being famous, as well as the "greed is good" mantra of financiers like the character of Gordon Gekko in Wall Street (Stone, 1987).

Despite my enjoyment of Schoenhals' (2019) thought experiment, I have three issues with this book. My first critique concerns his lack of engagement with existing work on utopias. From Dutch historian Rutger Bregman's (2018) Utopia for Realists, to sociologist Erik Olin Wright's (2010) Envisioning Real Utopias, there is a much larger conversation about the quest for a better world that this work should be embedded in. For instance, Wright explains that he began his thinking and writing about utopias in the 1990s as, "alternatives to existing structures of power, privilege and inequality," (p. x). Exploring where his ideas overlap and diverge from those of Wright and Bregman, among others, would have been enlightening for Schoenhals' project. Both Wright and Schoenhals, for instance, cite Wikipedia and worker cooperatives as examples of radically different kinds of institutions that are anticapitalistic, emancipatory, and provide evidence of "radical democratic egalitarian visions of an alternative social world," (Wright, p. 1). In addition to academic work on utopias, members of marginalized groups have at various times broken away from mainstream society, in order to establish societies that were closer to egalitarian, including the establishment of womyn's lands by radical feminists and utopian black communities, explored recently in Black Utopia by Alex Zamalin (2019).

My second critique is his rather cavalier reference to the potential need for population control in Utopia as a response to potential scarcity. Since his model society would guarantee basic subsistence to all people, the question of potential food and resource scarcities inevitably emerges. In addressing this kind of worse-case scenario of food scarcity, Schoenhals (2019) explains,

"If there is not enough food for everyone, then the world's population must be controlled. Many people feel that it is their right to have as many children as they want, but I am arguing that there is an even more basic right, the right of every child and adult to be able to eat enough to be free from the threat of hunger. Therefore, in the case of decreasing or insufficient global food supply, Utopia will institute mandatory population controls to reduce the population to match the carrying capacity of Earth," (p. 111).

Later he reiterates the point that, "the global population will be controlled, or reduced if necessary, so that there is enough land per capita and enough housing materials for all people," (p. 112).

In a utopian society that emphasizes compassion, joy, and happiness through the eradication of hierarchy, the suggestion that Utopia might have to engage in population control lands like a bomb. So many of Schoenhals' (2019) ideas are thoughtfully executed, including engagement with potential critiques that this one took me by complete surprise. Certainly, ecologists argue that the carrying capacity of the earth is already threatened due to population size. But suggesting population control as the answer is distressing for several reasons. First, the history of population 
control itself provides a cautionary tale for anyone seeking to limit hierarchy. In the past, population control has disproportionately targeted marginalized groups. Second, who will get to carry their pregnancies to term, and whose pregnancies will be terminated involuntarily? The process involved in answering this question will itself create additional forms of social hierarchy. Finally, this entire argument runs counter to Utopia's emphasis on interactive joy, since parenting is alleged to provide a significant source of joy and happiness. Schoenhals should have invested more attention toward addressing the potential threat of overpopulation and resource scarcity to his Utopia, as it is a very real threat to any society, where people's needs are aligned with earthly limitations. People can be educated to understand the threat of overpopulation in a society that values compassion and caring for their fellow Utopians first. In fact, we know that birth rates decline as educational and employment opportunities for women expand, so the idea that people can be motivated to limit their reproduction through education is not entirely novel.

Finally, maybe it is too much to ask out of any one book, but I would have liked to see a road map, of sorts, explaining how we get from here to there, especially since part of Schoenhals (2019) vision involves ending war and the nation state, as these are some of the major causes of hierarchy and human misery. Does Schoenhals envision a transition period between neoliberal, capitalist society and Utopia, similar to Marx's prediction that a socialist society would emerge from the demise of capitalism and predate the emergence of his vision of a fully equal communist society? While Schoenhals does not address this question, the current pandemic reveals the limitations of military power and nation states, where arbitrary national borders are insufficient in stopping the spread of the coronavirus; no one is safe, whether citizens of wealthy nations or poor nations. Military power clearly provides no protection. Whether or not, we successfully contain the virus will also likely expose the limitations of the global hierarchy - as wealthy nations gain early access to vaccines, purchasing billions of doses, and prompting a global call for vaccine equity. As of February 24, 2021, residents in just 10 countries have received $80 \%$ of shots, according to the United Nations (Shifrin \& Oh, 2021). And yet, the coronavirus will remain a global public health threat as long as masses of people remain unvaccinated; national hierarchies are failing us in the fight against COVID.

My critiques aside, it is a joy to read a work that engages intellectually with what it might require to create a more just and equal society that prioritizes human happiness and meets the needs of its citizens. As educators concerned with social justice, surely we can accept the fundamental argument that everyone deserves to love and be loved. His simple, yet powerful, statement in the concluding chapter that, "we need to interact affirmatively with others, in order to feel happy. Thus, we cannot make ourselves feel happy, if social conditions interfere with the quality of our relationships with other humans" (Schoenhals, 2019, p. 255), strikes a powerful chord, particularly in the era of COVID.

And yet, current social conditions interfere with our relationship to the natural world and life itself, leading me to ask, can we have a utopian society without addressing the environmental crisis? While Schoenhals' refuses to privilege economic equality or other status hierarchies in his conceptualization of Utopia, in the current era, one must privilege ecological sustainability over all other crises, since 
climate change threatens the habitability of the planet. The growth in human population, resource consumption, and fossil fuel energy use, among other environmental trends, has so devastated the functioning of the earth's natural systems that their ability to maintain the air, water, soil, biodiversity, and climate stability on which human societies depend, is no longer in question. A utopian society concerned with the eradication of hierarchy, must begin with human's domination over and exploitation of the natural world that has left us in such a precarious position.

\section{Declarations}

Conflict of interest The author reports no conflict of interest, nor research involving human participations or animals, and no informed consent needed in this paper.

\section{References}

Branson-Potts, H., Reyes-Velarde, A., Stiles, M., and A.J. Campa. (2020, May 17). The price of being 'essential:' Latino service workers bear brunt of coronavirus. The Los Angeles Times. https://latim es.com/california/story/2020-05-17/latino-essential-workers-coronavirus.

Bregman, R. (2018). Utopia for realists: How we can build an ideal world (Reprint). Back Bay Books.

Cohen, Rachel M. (2021, March 11). The coronavirus made the radical possible. New York Times. https:// www.nytimes.com/2021/03/11/opinion/covid-eviction-prison-internet-policy.html.

Godoy, M. \& D. Wood. (2020, May 30). What do coronavirus racial disparities look like state by state? NPR. https://www.npr.org/sections/health-shots/2020/05/30/865413079/what-do-coronavirusracial-disparities-look-like-state-by-state.

Hummer, Robert. (2020, May 22). The COVID-19 health toll in the United States: Exposing racism yet again. The Department of Sociology. http://sociology.unc.edu/the-covid--19-health-toll-in-theunited-states-exposing-racism-yet-again.

Jan, Tracy. (2020, May 9). This is how economic pain is distributed in America. The Washington Post. https://www.washingtonpost.com/business/2020/05/09/jobs-report-demographics.

Kallberg, Arne. (2020, May 22). COVID-19, precarity, and worker power. The Department of Sociology. http://sociology.unc.edu/covid-19-precarity-and-worker-power.

Schoenhals, M. (2019). Work, Love, and Learning in Utopia: Equality Reimagined. Routledge.

Shifrin, N. \& Oh, R. (2021, Feb. 24). Global Disparities Highlighted by Uneven Access to COVID Vaccines. PBS Newshour. https://www.pbs.org/newshour/show/global-disparities-highlighted-by-uneven-access-to-covid-vaccines.

Stone, O. (1987). Wall street. $20^{\text {th }}$ Century Studios.

Wright, E. O. (2010). Envisioning real utopias. Verso.

Yang, A. (2018). The war on normal people: The truth about America's disappearing jobs and why universal basic income is our future. Hachette Books.

Zamalin, A. (2019). Black utopia: The history of an idea from black nationalism to Afrofuturism. Columbia University Press.

Publisher's Note Springer Nature remains neutral with regard to jurisdictional claims in published maps and institutional affiliations. 